\section{Archives and citation miss equal authors}

It is now common practice to include 'equal contributions' footnotes in papers that have multiple first or senior authors. Unfortunately, this information is not preserved by the archiving and citation processes. The omission diminishes the roles of equal but subsequently listed authors, discouraging scientists from working in collaborations and teams - the backbone of modern scientific progress.

Equal-authorship details can currently be found only in the papers themselves. These details are not available on indexing sites or in referenced citations, which are increasingly the main source of information for literature searches.

To rectify this oversight, indexers need publishers to code author-status information in a standard format. For example, journals could include an asterisk beside authors' names to indicate equal contributions for article-citation purposes. We call on all journals and indexers such as PubMed, Google Scholar and Thomson Reuters Web of Science to update their systems to reflect shared authorship. Brian D. Brown, Miriam Merad Icahn School of Medicine at Mount Sinai, New York, USA. brian.brown@mssm.edu

\section{Design buildings for rapid evacuation}

In today's terrorism-prone world (see, for example, Nature 528, 7-8; 2015 and Nature 528, 20-21; 2015), it is becoming increasingly important to ensure that buildings are designed to be speedily evacuated in an emergency.

Evacuation modelling is a relatively new field that uses computational tools to predict human behaviour in a stricken building. Algorithms represent the range of people's possible reactions in the event of such a disaster (see, for example, E. D. Kuligowski et al. US National Institute of Standards and Technology Technical Note 1680; 2010). Models provide information on optimal evacuation strategies and allow buildings to be tested using real and hypothetical evacuation scenarios.

Making evacuation modelling mandatory in the design and assessment of existing and planned buildings that could be at risk would minimize the impact of attacks on occupants. Enrico Ronchi Lund University, Sweden.

enrico.ronchi@brand.lth.se

\section{Common doctorates across Europe}

The German medical doctorate system is not the only element that needs changing to overcome the ills that you discuss (see Nature 527, 7; 2015). In our view, a European approach offers the best cure.

We suggest that Germany's medical degree should be modified to lead to a common European medical qualification: the vocational degree of Doctor of Medicine. Postgraduate medical research should be part of a different common European qualification: the academic degree of Doctor of Philosophy.

Scientific quality would be guaranteed if the criteria for attaining degrees were to be standardized across Europe, and if specialist postgraduate medical colleges were widely set up. Students and clinicians would then also be able to pursue their divergent scientific interests more easily.

A European core curriculum devised along these lines would reduce excessive pressure on students, enhance the mobility of students and graduates, and foster the growth of excellent health care and science. The International Federation of Medical Students' Associations and the European Medical
Students' Association have already laid the foundations for such a curriculum (see J. Hilgers et al. Med. Teach. 29, 270-275; 2007).

Stefan U. Hardt, Jannis Papazoglou, Benedikt W. Pelzer European Medical Students' Association, Brussels, Belgium. pmo@emsa-europe.eu

\section{Clean energy enters virtuous cycle}

Governments promised on 30 November to almost double global funding for clean-energy research (see go.nature.com/ n4qdsw). Meanwhile, the very act of deploying emissionscutting technologies to meet countries' climate pledges at the recent United Nations summit in Paris is likely to spur major innovation.

Such technological advances mean that cutting emissions can drive down the cost of further cuts in emissions (see go.nature. com/j8ueaj). For example, the price of photovoltaic modules for solar energy has fallen by $85 \%$ since 2000 as markets have grown; electricity costs from wind are now comparable to those from coal; and energystorage technologies are improving.

Publicly funded research and development, early investment by the private sector, and efficient deployment are all crucial for innovation. Market growth in renewable energy is largely driven by government policies, which have unleashed private companies' research ingenuity and achieved economies of scale and greater productivity (see also J. E. Trancik Nature 507, 300-302; 2014).

Recognizing the mutual reinforcement of cutting emissions and improving clean energy is essential for negotiating a long-term, ambitious climate deal. As global efforts add up, falling costs should allow for an international agreement to phase in emissions cuts at a rate that matches each nation's stage of economic development.

Jessika E. Trancik Massachusetts Institute of Technology, Cambridge, USA. trancik@mit.edu

\section{Crowdfunded trials doubly scrutinized}

We disagree that crowdfunding of clinical trials is ethically questionable (P. Y. Cheah Nature 527, 446; 2015). Participants are still governed by the same high standards of research integrity as traditionally funded recipients - but with the added scrutiny that comes with public engagement (see, for example, N. Siva Lancet 384, 1085-1086; 2014).

Cheah criticizes crowdfunding of clinical trials because it risks backing studies that are of limited importance and applicability. However, it is this very feature that offers an opportunity to fund trials for rare or emerging tropical diseases that might not otherwise attract financial support (see, for example, T. S. van der Werf et al. Bull. World Health Organ. 83, 785-791; 2005).

David Hawkes University of Melbourne; and Florey Institute of Neuroscience and Mental Health, Victoria, Australia.

Melanie Thomson Deakin University, Victoria, Australia. m.thomson@deakin.edu.au

\section{CORRECTION}

The Outlook article 'Research without prejudice' (Nature 525, S12-S13; 2015) incorrectly stated that the approval of the US National Institute on Drug Abuse (NIDA) is required for US cannabis trials. In fact, NIDA provides cannabis for every project that has completed the government-mandated approval process. The article also implied that NIDA was holding up the start of a trial led by Sue Sisley, but the delay is caused by other circumstances. 